\begin{tabular}{lcc}
\hline item & OR & Cl 95\% \\
\hline Arthritis history or presence & 2.9 & {$[11.2-30.9]$} \\
csDMARD use during the past 6 months & 5.2 & {$[2.9-9.1]$} \\
Calcaneal enthesitis history or presence & 6.7 & {$[3.0-14.7]$} \\
BASDAI > median & 1.08 & {$[1.05-1.11]$} \\
BASFI > median & 1.04 & {$[1.02-1.06]$} \\
SF36 phys <median & 0.92 & {$[0.87-0.97]$} \\
Systemic steroids during the past 6 & 5.49 & {$[2.93-$} \\
months & & $10.28]$ \\
Sacro iliac erosion (MRI central reading) & 0.02 & $0.004-$ \\
& & $0.13]$ \\
mSASSS (central reading) & 0.37 & {$[0.21-0.66]$} \\
\hline
\end{tabular}

After 5 years, 138 cases were recorded in 480 patients with complete follow-up : prevalence $28.75 \%$ [Cl 95\% 24.75-32.75], with estimated incidence of $1.7 / 100$ patient-years. At 5 years, dactylitis was significantly associated (multivariate analysis) with : Achilles enthesitis (OR : 3.3), history of psoriasis (OR: 3.9), cumulative number of ASAS criteria (OR: 7.2), modified New York criteria fulfillment (OR: 0.35), DMARD use (OR: 2.7) and elevated CRP (OR:0.9).

Conclusion: In the DESIR cohort of patients suspected for early SpA, history of dactylitis is present in $13.7 \%$ of the cases at baseline and an estimated incidence of $1.7 / 100$ p-y over 5 years. It is an early feature associated with peripheral involvement, and associated with more burden of the disease, more frequent use of DMARDs and steroids, but with less structural damage.

Disclosure of Interests: Daniel Wendling: None declared, Clément Prati: None declared, Alain Saraux Consultant for: Roche SAS, Speakers bureau: Chugai Pharma France, Anna Moltó: None declared, thao pham: None declared, maxime dougados Grant/research support from: Eli Lilly and Company, Pfizer, AbbVie, and UCB Pharma, Consultant for: Eli Lilly and Company, Pfizer, AbbVie, and UCB Pharma, xavier guillot: None declared

DOI: 10.1136/annrheumdis-2019-eular.3166

\section{SAT0357 PREVALENCE OF RADIOGRAPHIC ENTHESEAL LESIONS AT THE HIP AND PELVIC REGION IN PATIENTS WITH ANKYLOSING SPONDYLITIS}

Freke Wink $^{1,2}$, Thomas Diemel ${ }^{2}$, Suzanne Arends ${ }^{1,2}$, Anneke Spoorenberg $^{1,2}$. ${ }^{1}$ Medical Center Leeuwarden, Rheumatology, Leeuwarden, Netherlands;

${ }^{2}$ University Medical Center Groningen, Rheumatology and Clinical Immunology, Groningen, Netherlands

Background: Enthesitis is one of the features of ankylosing spondylitis (AS). High prevalence of structural and inflammatory ultrasound lesions of peripheral entheses are found in AS patients. Furthermore, plain radiographs provide good imaging of peripheral enthesopathy at well-defined skeletal sites1. There are several entheseal sites at the pelvis and hip region, but little is known about the presence of structural entheseal anomalies at these sites in AS.

Objectives: Our aim was to investigate the prevalence of radiographic entheseal lesions at the hip and pelvic region in patients with AS.

Methods: The present analysis was performed in 214 patients from the Groningen Leeuwarden Axial SpA (GLAS) cohort study, who were included between November 2004 and December 2010 and had available anteroposterior (AP) pelvis radiographs at baseline. All patients fulfilled the modified New York criteria for AS. Radiographs were scored by two trained readers blinded for patient characteristics and treatment. Anomalies with absolute agreement were reported. The entheseal sites scored were: trochanter major, trochanter minor, os ischium, crista iliaca, both left and right side and symphysis pubis. The following 3 anomalies were scored: cortical irregularities/erosions, calcifications and enthesophytes.

Results: Of the 214 patients, 148 (69\%) were male, mean age was 42.5 \pm 11.6, 171 (80\%) were HLA-B27 positive and median symptom duration was 16 years (IQR 8-24). Reader agreement on the entheseal lesions was moderate to excellent with Cohen's kappa's between 0.474 and 0.882. 122 patients $(51 \%)$ showed enthesopathy with 309 lesions in total. The most prevalent lesions were irregularities/erosions $(n=220 ; 71 \%)$, followed by enthesophytes $(n=71 ; 23 \%)$ and calcifications $(n=16 ; 5 \%)$. Most lesions were found at the os ischii $(n=168 ; 54 \%)$, followed by the tuberculum majus $(n=42 ; 14 \%)$, crista iliaca $(n=40 ; 13 \%)$, tuberculum minus $(n=30 ; 10 \%)$ and symphysis pubis $(n=29 ; 9 \%)$.

Conclusion: In this cohort of established AS patients, a high prevalence of radiographic entheseal lesions at the hip and pelvic region was found. Irregularities and erosions were most frequently found, especially at os ischium. These new findings concerning structural entheseal lesions at the pelvis and hip region contributes to the knowledge of entheseal involvement in AS.

\section{REFERENCES}

[1] Voudouris KP, Sidiropoulos P, Vounotripidis P, Arvanitakis M. Enthesial fibrocartilage - bone interaction: a radiographic study of selected sites of nonsynovial peripheral enthesopathy. J Musculoskelet Neuronal Interact. 2003 Mar;3(1):89-100.

Disclosure of Interests: Freke Wink Consultant for: Abbvie, Janssen, Thomas Diemel: None declared, Suzanne Arends Grant/research support from: Grant/research support from Pfizer, Anneke Spoorenberg Grant/ research support from: Received unrestricted grants from Pfizer, Novartis and Abbvie pharmaceuticals. They had no influence in design and conduct of the study., Consultant for: Abbvie, Pfizer, MSD,

UCB, and Novartis

DOI: 10.1136/annrheumdis-2019-eular.7965

\section{SAT0358 EROSION MIGHT INCREASE PROBABILITY OF POSITIVE AXIAL SPONDYLOARTHRITIS (SPA) DIAGNOSIS IN PATIENTS WITH EARLY INFLAMMATORY BACK PAIN(IBP). A PROSPECTIVE 3.5 YEAR FOLLOW UP OF 133 PATIENTS}

Liliya Yankova Komsalova ${ }^{1}$, Pilar Martinez ${ }^{2}$, Jose Fermin Gomez ${ }^{2}$ Antonio Valdivia ${ }^{2} .{ }^{1}$ Hospital Marina Salud, Denia, Rheumatology, Denia, Spain; ${ }^{2}$ Hospital Marina Salud, Denia, Radiology, Denia, Spain

Objectives: To analyse sensitivity, specificity and predictive values of inflammatory back pain (IBP), positive HLA B27 antigen, increased Creactive protein $(\mathrm{CRP})$, clinical features (CF) such as peripheral arthritis, dactylitis, psoriasis, uveitis, inflammatory bowel disease and enthesitis, familial history $(\mathrm{FH})$ of SPA and assess probabilities to develop SPA. To evaluate the impact of chronic (T1) MRI lesions in early diagnosis of SPA

Methods: We prospectively collected and followed up 133 patients referred to our department with suspicion of SPA from September 2014 to March 2018. Data such as IBP, HLA B27 antigen, increased $\mathrm{CRP}, \mathrm{CF}, \mathrm{FH}$ and sacroiliac X-rays were collected for each patient. STIR and T1 MRI imaging were separately and independently evaluated by a rheumatologist and two radiologists. In case of disagreement, agreement between two readers was regarded as conclusive MRI STIR sacroiliac joints (SI) images were assessed in a semi-qualitative way as follows: 1) strongly positive MRI imaging(SPMRI) patients with at least 2 highly specific bone marrow oedema(BME) lesions, easily classifiable as SPA. 2) Weakly positive MRI imaging (WPMRI): patients with at least 2 tiny BME lesions, suggestive, but not easily classifiable as SPA. 3) Clearly negative MRI imaging: patients without any of those features. T1 SI MRI images were assessed for erosion, fat metaplasia, backfill and sclerosis in a qualitative way as positive, if there were 1 or more than one, or negative, if there were none of those lesions.

Results: The average age in our study was 38.9 years. $47(35.3 \%)$ patients received diagnosis axial SPA. Radiographic sacroiliitis had 8 (17\%). Sensitivity (St), specificity (Sf) and predictive positive values (PPV) were found as follows for each item $(\mathrm{p}<0.001)$ : IBP: $83 \%$ St 81.4\% Sf, 71\%PPV, positive HLA B27: $49 \%$ St, $80 \%$ Sf, $57.5 \%$ PPV, increased CRP: $40.4 \%$ St, $93 \%$ Sf, $76 \%$ PPV, and CF: $36.2 \%$ St $91 \%$ Sf, 68\%PPV. Multivariate logistic regression binary analysis applied to the group of patients with non-radiographic SPA showed Odds Ratios for positive diagnosis, 64.8 for IBP $(p=0.000), 9.4$ for increased CRP $(p=0.005)$ and 11.9 for CF $(p=0.006)$. For the total group of patients the Odds Ratios were as follows: 49.2 for IBP 
$(p=0.000), \quad 10.3$ for increased CRP $(p=0.002)$ and 11.3 for CF $(p=0.002)$. STIR MRI imaging assessment proved acceptable sensitivity (79\%), excellent specificity (94\%), and high PPV (88\%) for SPMRI $(p<0.001)$. WPMRI displayed better sensitivity $(87 \%)$ nonetheless, specificity $(67 \%)$ and PPV decreased $(59 \%) \quad(p<0.001)$. T1 MRI examination showed reasonable sensitivity (72\%) excellent specificity (97\%) and high PPV $(85 \%)$ for erosion $(p<0.001)$. Sensitivity for backfill was lower $(32 \%)$, but specificity (100\%) and PPV (100\%) were excellent $(p<0.001)$. Association, erosion and SPMRI pointed out a highly strong specificity (100\%) and PPV (100\%), however decreased sensitivity $(51 \%) \quad(p<0.001)$. Association, erosion and WPMRI significantly increased specificity (98\%) and PPV (94\%), although slightly decreased sensibility $(64 \%)(\mathrm{p}<0.001)$. Inter-observer agreement was higher for STIR MRI performance $0.70(95 \% \mathrm{CI} 0.59 ; 0.80)$, and lower for T1 0.47 (95\% Cl 0.35; 0.59).

Conclusion: At the onset, IBP, increased CRP, CF and IBD might be good indicators for selecting patients with a higher likelihood of positive diagnosis. Strongly positive SI MRI imaging is highly specific, brings acceptable sensibility and may be an excellent tool for early diagnosis of SPA. Weakly positive MRI STIR imaging might be helpful to detect patients with early SPA but lacks specificity. Early detection of erosion adds additional value to the STIR MRI reading, enhancing the specificity and increasing the probability of positive SPA diagnosis Disclosure of Interests: None declared

DOI: 10.1136/annrheumdis-2019-eular.1540

\section{SAT0359 THE AGREEMENT BETWEEN CT AND BONE SCINTIGRAPHY IN DETECTING OSTEOARTICULAR LESIONS IN SAPHO SYNDROME}

Yuqian $\mathrm{Ye}^{1}$, LI Chen ${ }^{2}$, Yihan $\mathrm{Cao}^{2}$, Wen Zhang ${ }^{2}$, Nan Wu'², Weihong Zhang ${ }^{3}$, Wenrui Xu ${ }^{2} .{ }^{1}$ Peking Union Medical College, Beijing, China; ${ }^{2}$ Peking Union Medical College Hospital, Beijing, China; ${ }^{3}$ Beijing Hospital, Beijing, China

Background: Computed tomography (CT) and ${ }^{99 m} \mathrm{Tc}-\mathrm{MDP}$ bone scintigraphy are commonly used to detect osteoarticular lesions and the typical bull's head sign of the anterior chest in the diagnosis of Sapho syndrome ${ }^{[1,2]}$. Since bone scintigraphy visualizes high radioactive uptake which basically indicates inflammatory lesions, and CT demonstrates the structural lesions in bones and joints, the findings of the two modalities usually do not correspond with each other ${ }^{[3,4]}$. However, little is known about the agreement between CT and bone scintigraphy on the findings of osteoarticular lesions in the patients of Sapho syndromes.

Objectives: To determine the agreement between CT and bone scintigraphy on the findings of osteoarticular lesions in Sapho syndrome.

Methods: A total of 68 patients who met the standard criteria of Sapho syndrome proposed by Kahn and Khan ${ }^{[5]}$ with simultaneous (the interval $<1$ month) whole spinal CT scan and bone scintigraphy were recruited in Peking Union Medical College from 2015 to 2016. Every CT or scintigraphy result was evaluated by at least two specialists independently and blindly. CT scan and scintigraphy results of all patients were evaluated for whether the following osteoarticular structures were involved: the clavicle, sternoclavicular joints, sternocostal joints, sacroiliac joints and all vertebra. The respective involvement frequencies and the kappa value of agreement were calculated.

Results: Involved vertebra on the CT scan present as corner lesions or endplate lesions. Involved joints on the CT scan present as narrowed articular spaces or damaged articular facets. CT scan is more sensitive to detect the involvement of vertebra and sternocostal joints, but less sensitive for sternoclavicular and sacroiliac lesions than bone scintigraphy. Kappa value was calculated to assess the agreement between CT and bone scintigraphy (Table. 1). It ranges from 0.103 to 0.593 over different structures, indicating a slight to moderate agreement between the two tests.
Table 1. Agreement analysis between CT and bone scintigraphy

\begin{tabular}{|c|c|c|c|c|c|}
\hline $\begin{array}{l}\text { Structures/ } \\
\text { Locations }\end{array}$ & $\begin{array}{l}\text { Involvement } \\
\text { frequency } \\
\text { on CT }\end{array}$ & $\begin{array}{c}\text { Involvement } \\
\text { frequency } \\
\text { on bone } \\
\text { scintigraphy }\end{array}$ & $\begin{array}{c}\text { Measure of } \\
\text { agreement, } \\
\kappa \text { value }\end{array}$ & $\begin{array}{c}\mathrm{P} \\
\text { value }\end{array}$ & \\
\hline $\begin{array}{l}\text { Cervical } \\
\text { vertebra }\end{array}$ & $14 / 68$ & $2 / 68$ & 0.209 & 0.055 & \\
\hline $\begin{array}{l}\text { Thoracic } \\
\text { vertebra }\end{array}$ & $29 / 68$ & $15 / 68$ & 0.103 & 0.343 & \\
\hline $\begin{array}{l}\text { Lumbar } \\
\text { vertebra }\end{array}$ & $33 / 68$ & $19 / 68$ & 0.464 & 0.001 & \\
\hline Sacral vertebra & $20 / 68$ & $3 / 68$ & 0.199 & 0.006 & \\
\hline Sternal angle & $27 / 68$ & $24 / 68$ & 0.593 & $<$ & 0.001 \\
\hline Clavicle & $3 / 68$ & $4 / 68$ & 0.248 & 0.039 & \\
\hline $\begin{array}{l}\text { Left } \\
\text { sternoclavicular } \\
\text { joint }\end{array}$ & $27 / 68$ & $36 / 68$ & 0.274 & 0.019 & \\
\hline $\begin{array}{c}\text { Right } \\
\text { sternoclavicular } \\
\text { joint }\end{array}$ & $26 / 68$ & $40 / 68$ & 0.209 & 0.06 & \\
\hline $\begin{array}{l}\text { Left } \\
\text { sternocostal } \\
\text { joint }\end{array}$ & $40 / 68$ & $6 / 68$ & 0.024 & 0.683 & \\
\hline $\begin{array}{l}\text { Right } \\
\text { sternocostal } \\
\text { joint }\end{array}$ & $39 / 68$ & $8 / 68$ & 0.075 & 0.283 & \\
\hline $\begin{array}{l}\text { Left sacroiliac } \\
\text { joint }\end{array}$ & $8 / 68$ & $14 / 68$ & 0.145 & 0.208 & \\
\hline $\begin{array}{l}\text { Right sacroiliac } \\
\text { joint }\end{array}$ & $9 / 68$ & $18 / 66$ & 0.415 & $<$ & 0.001 \\
\hline
\end{tabular}

The two tests have comparable detection rates for the involvement of sternal angle with a highest kappa value (0.593). But there are huge differences at other structures with extremely low kappa value, which suggests the routine bone scintigraphy for diagnosis cannot replace a CT scan in terms of evaluating osteoarticular lesions.

Conclusion: The agreement between CT and bone scintigraphy was poor, indicating an importance of implementing routine CT tests in Sapho syndrome.

\section{REFERENCES}

[1] Sugimoto H, Tamura K, Fujii T. The SAPHO syndrome: defining the radiologic spectrum of diseases comprising the syndrome. EurRadiol 1998:8:800-6.

[2] Salles M, Olive A, Perez-Andres R, Holgado S, Mateo L, Riera E, et al. The SAPHO syndrome: a clinical and imaging study. ClinRheumatol 2011;30:245-9.

[3] Akisue T, Yamamoto T, Marui T, et al. Lumbar spondylodiscitis in SAPHO syndrome: multimodality imaging findings. J Rheumatol 2002;29 (5):1100-1.

[4] Depasquale R, Kumar N, Lalam RK, et al. SAPHO: What radiologists should know. ClinRadiol 2012;67(3):195-206.

[5] Kahn MF, Khan MA. The SAPHO syndrome. BaillieresClinRheumatol 1994; 8:333-62.

Disclosure of Interests: None declared

DOI: 10.1136/annrheumdis-2019-eular.1095

\section{Psoriatic arthritis}

\section{SAT0360 REMISSION IN PSORIATIC ARTHRITIS: DEFINITION AND PREDICTORS}

Samar Al Harbi ${ }^{1}$, Ker-Ai Lee ${ }^{2}$, Vinod Chandran ${ }^{1}$, Richard Cook ${ }^{2}$, Dafna

D. Gladman ${ }^{1} .{ }^{1}$ University of Toronto, Toronto, Canada; ${ }^{2}$ University of Waterloo, Waterloo, Canada

Background: No validated definition of remission exists for psoriatic arthritis (PsA) to date. We previously identified $17.6 \%$ of our patients as 